\title{
Photodegradable Toners for E lectrophotography III. Accelerated Photodegradation and Suppressed Photocrosslinking of Matrix Resin-Their Dependence on Polymer Composition, UV-light Source, and Irradiation Conditions
}

\author{
Kazuyuki Sugita, ${ }^{\dagger}$ Toshiko Hosoda, Masahito KushidA, \\ Kieko HARADA, and Kyoichi SAITO \\ Department of Materials Technology, Chiba University, 1-33 Yayoi-cho, Inage-ku, Chiba 263-8522, Japan
}

(Received July 31, 2003; Accepted September 19, 2003)

\begin{abstract}
Phenyl isopropenyl ketone (PIPK) was terpolymerized with styrene and n-butyl acrylate. Clear $1.6 \mu \mathrm{m}$ thick polymer layers coated on glass plates were found to be removed by 2-3 times of repeated cycles of $254 \mathrm{~nm}$ or $222 \mathrm{~nm}$ deep ultraviolet irradiation for $3 \mathrm{~min}$ at $80-120^{\circ} \mathrm{C}$ and brushing-off. The polymer layer irradiated under some conditions could not be detached from the substrate, and crosslinking was observed to take place in parallel with degradation during the irradiation. From the experiments with PIPK-methyl methacrylate copolymer as a model polymer, the optimum PIPK content for easy detaching was found to be around $11 \mathrm{~mol} \%$. Further, the preferable light source and irradiation temperature were determined for effective photodegradation with suppressing photocrosslinking, and the reaction scheme was elucidated from UV-spectral and molecular-weight changes and quantum yields for benzoyl side-group removal and for main-chain scission.

KEY WORDS Phenyl Isopropenyl Ketone (PIPK) / PIPK-Styrene-Butyl Acrylate Terpolymer / Model Copolymer / Deep Ultraviolet Irradiation / Side-Group Removal / $\beta$-Scission of Main Chain / Direct $\mathrm{C}-\mathrm{C}$ Bond Scission /
\end{abstract}

In the case of the toner (powder ink) image of photocopy, the powders containing colorant particles inside are fixed on the substrate or to each other by partial fusion of matrix resin on the toner surface. It is then easy to detach the image and to recover the substrate by unbinding the fixed colorants. The image of photodegradable toners was proposed to be detached from the substrate by mechanical action after near/mid ultraviolet (UV) or deep UV (DUV) light irradiation for reuse of the poly(ethylene terephthalate) (PET) or paper substrate.

In the previous papers, ${ }^{1,2}$ we terpolymerized phenyl isopropenyl ketone (PIPK), as a photodegradable monomer unit, with styrene (St) and n-butyl acrylate $(\mathrm{BuA})$ which are the main components of the conventional polymer for the matrix resin, and measured the clear terpolymer layer on a glass plate for spectral and molecular-weight (MW) changes as well as photodegradability by DUV irradiation. Benzoyl sidegroup removal, main-chain scission, and detachability of the polymer layer from the substrates were observed to be accelerated by $254 \mathrm{~nm}$ DUV irradiation at an elevated temperature. A $1.6 \mu \mathrm{m}$ thick polymer layer was removed successfully by $2-3$ times of repeated cycles of $3 \mathrm{~min}$ exposure at $100-150^{\circ} \mathrm{C}$ and brushing-off. However, some thin residual layer was formed and the ratio of $M_{\mathrm{w}} / M_{\mathrm{n}}$ increased larger than 3.0 after irradi- ation at and above $160^{\circ} \mathrm{C}$, suggesting acceleration of crosslinking at the same time. Further, substitution of BuA with n-butyl methacrylate (BuMA) in the terpolymer could not suppress the residual layer formation, ${ }^{2}$ which indicated crosslinking to proceed by hydrogen abstraction not only from BuA, but also from St or other units in the polymer chain.

In this paper, PIPK-MMA (methyl methacrylate) copolymers with various compositions, which have no vinyl monomer unit with $\alpha$-hydrogen atom, were prepared as a model polymer, and the most suitable PIPK content was determined for photodegradation and easy detaching, rather suppressing photocrosslinking. Further, the degradation and crosslinking mechanism was clarified by changing the DUV light source and irradiation conditions. Then terpolymer with the optimum PIPK content was prepared, and photochemistry of the matrix terpolymer was studied during $222 \mathrm{~nm}$ and $254 \mathrm{~nm}$ DUV irradiation, comparing with that of the model copolymer.

\section{EXPERIMENTAL}

\section{Polymer and Specimen Preparation}

PIPK was copolymerized with MMA or terpolymerized with $\mathrm{St}$ and $\mathrm{BuA}$ in suspension by using $\alpha, \alpha^{\prime}$ azobis(isobutyronitrile) (AIBN) and PVA as the initia-

${ }^{\dagger}$ To whom correspondence should be addressed (Tel/Fax: +81-43-290-3437, E-mail: ksugita@faculty.chiba-u.jp). 
Table I. Characteristics of PIPK-MMA copolymer and PIPK terpolymer

\begin{tabular}{cccccrr}
\hline \multicolumn{2}{c}{ PIPK:MMA } & & & & & \\
\multicolumn{2}{c}{ PIPK:St:BuA ${ }^{\mathrm{a}}$} & $M_{\mathrm{w}}$ & \multicolumn{1}{c}{$M_{\mathrm{n}}$} & $M_{\mathrm{w}} / M_{\mathrm{n}}$ & $T_{\mathrm{g}} /{ }^{\circ} \mathrm{C}$ & $T_{\mathrm{s}} /{ }^{\circ} \mathrm{C}$ \\
\hline PM05 & $5: 95$ & 26900 & 12100 & 2.2 & 121.3 & 180.0 \\
PM11 & $11: 89$ & 36400 & 20700 & 1.7 & 98.4 & 169.1 \\
PM15 & $15: 85$ & 21200 & 14400 & 1.5 & 115.4 & 159.0 \\
PM20 & $20: 80$ & 11100 & 6600 & 1.7 & 58.7 & 86.0 \\
\hline TerM & $11: 70: 19$ & 35000 & 18000 & 1.9 & 75 & 102 \\
\hline
\end{tabular}

${ }^{\mathrm{a}}$ in molar ratio.

tor and the stabilizer, respectively, similarly as stated before. ${ }^{2,3}$ The products were reprecipitated from benzene/ethanol systems, and characterized by the methods as described in the previous paper. ${ }^{2}$ The polymer data are summarized in Table I. Clear polymer layers were spincoated from tetrahydrofuran solutions onto glass or quartz plates and prebaked at $90{ }^{\circ} \mathrm{C}$.

\section{DUV Irradiation and Photodegradability}

A $1.6 \mu \mathrm{m}$ thick polymer layer was irradiated in the air with a Toshiba low-pressure mercury lamp emitting a $254 \mathrm{~nm}$ monochromatic radiation, or in nitrogen with an excimer lamp of USHIO $\mathrm{KrCl}$ type, the emission from which can be regarded as a narrow band of radiation centered at $222 \mathrm{~nm}$. The light intensity was adjusted to $0.65 \mathrm{~mW} \mathrm{~cm}^{-2}$ in both cases. Detachability of the polymer layer was evaluated by repeated cycles of DUV irradiation at a given temperature for a given time and rubbing-down 100 times with a painting brush.

\section{Measurements of Side-Group Removal and Main- Chain Scission and Calculation of Quantum Yields}

Concentration of the remaining benzoyl groups was estimated from the absorbance at $242 \mathrm{~nm}$, and the number of absorbed photons was from that at $254 \mathrm{~nm}$ or $222 \mathrm{~nm}$ in the UV spectrum. The number of the main-chain scission events was obtained from numberaveraged MW's measured by GPC before and after DUV irradiation. The quantum yields for sidegroup removal, $\phi \mathrm{sr}$, and for main-chain scission, $\phi \mathrm{cs}$, were calculated by the method stated in the previous papers. ${ }^{2,3}$

\section{RESULTS AND DISCUSSION}

\section{Photodegradation of PIPK-MMA Model Copolymer by} $254 \mathrm{~nm}$ and $222 \mathrm{~nm}$ DUV Irradiation

Detachability of the Polymer Layer from the Substrate. When the layer was irradiated with $254 \mathrm{~nm}$ DUV light, photodegradation was the major reaction: the layer was detached from the substrate in most cases, but some thin residual layer was observed to remain with the copolymer containing 20 mol\% PIPK, PM20, at or above $140{ }^{\circ} \mathrm{C}$. The results are shown in the upperleft part of Table II.

At first, we expected that the detachability will be more improved, as the PIPK content increased and as the temperature during DUV irradiation increased. The detachability with PM20 was found not always to be higher than those with the copolymers of less PIPK content, PM15, PM11, and PM05. Formation of the residual layer was observed with PM20 irradiated at higher temperature. The most suitable temperature to accelerate the detachability of PM1 1 was $130-150{ }^{\circ} \mathrm{C}$ and 30-50 degree above its glass transition temperature, $T_{\mathrm{g}}$. In this way, the optimum PIPK content and the optimum temperature for detaching did exist unexpectedly.

The results after $222 \mathrm{~nm}$ DUV irradiation are indicated in the upper-right part of Table II. The detachability was higher than that after $254 \mathrm{~nm}$ DUV irradiation, and complete removal of the layer was observed with PM05 at $80{ }^{\circ} \mathrm{C}$ and $120^{\circ} \mathrm{C}$, PM1 1 at $26^{\circ} \mathrm{C}$ and $80^{\circ} \mathrm{C}$, and PM15 at $26^{\circ} \mathrm{C}$ and $80^{\circ} \mathrm{C}$. The acceleration from those after $254 \mathrm{~nm}$ DUV irradiation may suggest improved probability of the main-chain scission or suppression of the crosslinking below $T_{\mathrm{g}}$.

$M W$ and MWD Changes by DUV Irradiation and Quantum Yield, $\phi c s$. Molecular weight (MW) decreased monotonously during $254 \mathrm{~nm}$ DUV irradiation, and the decreasing rate became larger, as the PIPK content increased and as the irradiation temperature became higher. Dependences of MW decrease on PIPK content and irradiation temperature are shown in Figures 1 and 2 (a), respectively.

Molecular-weight distribution (MWD), $M_{\mathrm{w}} / M_{\mathrm{n}}$, gradually increased above 2.0 with PM15 and PM20 at $150^{\circ} \mathrm{C}$ in Figure 1, and slightly above 2.0 with PM1 1 at $120^{\circ} \mathrm{C}$ and $150^{\circ} \mathrm{C}$ in Figure 2 (a). Since MWD above 2.0 suggests the probability of crosslinking, the residual layer formation of PM20 at $140-160^{\circ} \mathrm{C}$ in Table II coincided approximately with the MWD increase above 2.0.

The quantum yield calculated for main-chain scission, $\phi$ cs, is shown in Figure 3(a). GPC data with PM20 were regarded as the values measured just on the soluble part of the DUV-irradiated copolymer, without counting the insoluble part (the residual layer remaining on the substrate), because the calculated $\phi$ cs's were higher than those expected from the results of the detachability indicated in Table II. Therefore, they are not cited in Figure 3 (a). When Figure 3 (a) was inspected carefully, it was noticed that the $\phi$ cs with PM1 1 was the highest at any temperature.

$222 \mathrm{~nm}$ DUV irradiation brought about a similar 
Table II. Detachability of the polymer layer from the substrate after several cycles of DUV irradiation and brushing ${ }^{\mathrm{a}}$

\begin{tabular}{|c|c|c|c|c|c|c|c|c|c|c|c|c|c|c|c|c|c|c|c|c|}
\hline \multicolumn{3}{|c|}{ DUV source } & \multicolumn{9}{|c|}{$254 \mathrm{~nm}$} & \multicolumn{9}{|c|}{$222 \mathrm{~nm}$} \\
\hline \multirow{2}{*}{$\begin{array}{l}\text { Exp. tim } \\
\text { Cycle }\end{array}$} & & \multirow[t]{2}{*}{$\overline{0}$} & \multicolumn{3}{|c|}{$1 \mathrm{~min}$} & \multicolumn{3}{|c|}{3} & \multicolumn{3}{|c|}{5} & \multicolumn{3}{|c|}{$1 \mathrm{~min}$} & \multicolumn{3}{|c|}{3} & \multicolumn{3}{|c|}{5} \\
\hline & & & $\times 1$ & $\times 2$ & $\times 3$ & $\times 1$ & $\times 2$ & $\times 3$ & $\times 1$ & $\times 2$ & $\times 3$ & $\times 1$ & $\times 2$ & $\times 3$ & $\times 1$ & $\times 2$ & $\times 3$ & $\times 1$ & $\times 2$ & $\times 3$ \\
\hline \multirow{4}{*}{ PM05 } & $26^{\circ} \mathrm{C}$ & $\times$ & $x$ & $x$ & $\triangle$ & $x$ & $\triangle$ & $\triangle$ & $x$ & $\triangle$ & $\triangle$ & $x$ & $x$ & $\triangle$ & $\triangle$ & $\triangle$ & O & $\triangle$ & O & O \\
\hline & 80 & & $\times$ & $\times$ & $\triangle$ & $\times$ & $x$ & $\triangle$ & $\times$ & $\triangle$ & $\bigcirc$ & $x$ & $\triangle$ & $\bigcirc$ & $\triangle$ & $\triangle$ & $\bigcirc$ & $\triangle$ & $\bigcirc$ & (0) \\
\hline & 120 & $\times$ & $\times$ & $\triangle$ & $\triangle$ & $\times$ & $\triangle$ & $\bigcirc$ & $\triangle$ & $\triangle$ & $\bigcirc$ & $\triangle$ & $\triangle$ & $\bigcirc$ & $\triangle$ & $\triangle$ & $\bigcirc$ & $\triangle$ & $\bigcirc$ & (0) \\
\hline & 150 & $\triangle$ & $\triangle$ & $\triangle$ & $\bigcirc$ & $\triangle$ & $\bigcirc$ & 0 & $\triangle$ & 0 & (a) & $\triangle$ & $\triangle$ & $\bigcirc$ & $\triangle$ & $\bigcirc$ & $\bigcirc$ & $\triangle$ & $\bigcirc$ & (0) \\
\hline \multirow{4}{*}{ PM11 } & $26^{\circ} \mathrm{C}$ & $x$ & $x$ & $\triangle$ & $\triangle$ & $x$ & $x$ & $\triangle$ & $\triangle$ & $\triangle$ & $\triangle$ & $x$ & $\triangle$ & $\triangle$ & $\triangle$ & $\triangle$ & 0 & $\triangle$ & 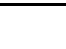 & (0) \\
\hline & 80 & $\times$ & $\times$ & $\triangle$ & $\triangle$ & $\times$ & $\triangle$ & $\triangle$ & $\times$ & $\triangle$ & $\triangle$ & $\triangle$ & $\bigcirc$ & $\bigcirc$ & $\triangle$ & $\bigcirc$ & $\bigcirc$ & $\triangle$ & $\bigcirc$ & (0) \\
\hline & 120 & $\triangle$ & $\triangle$ & $\triangle$ & $\bigcirc$ & $\triangle$ & $\bigcirc$ & $\bigcirc$ & $\bigcirc$ & $\bigcirc$ & (a) & $\triangle$ & 0 & $\bigcirc$ & $\triangle$ & $\bigcirc$ & (a) & $\bigcirc$ & $\bigcirc$ & (0) \\
\hline & 150 & $\triangle$ & $\triangle$ & 0 & 0 & 0 & 0 & (a) & 0 & (a) & (a) & $\triangle$ & 0 & 0 & $\triangle$ & (a) & (a) & $\triangle$ & 0 & (0) \\
\hline \multirow{4}{*}{ PM15 } & $26^{\circ} \mathrm{C}$ & $x$ & $x$ & $\triangle$ & $\triangle$ & $x$ & $x$ & $\triangle$ & $\triangle$ & $\triangle$ & 0 & $x$ & $\triangle$ & $\triangle$ & $\triangle$ & $\triangle$ & 0 & $\triangle$ & 0 & (0) \\
\hline & 80 & & $x$ & $\triangle$ & $\triangle$ & $\times$ & $\triangle$ & $\bigcirc$ & $\triangle$ & $\bigcirc$ & 0 & $\triangle$ & $\triangle$ & $\bigcirc$ & $\triangle$ & $\bigcirc$ & $\bigcirc$ & $\triangle$ & $\bigcirc$ & (a) \\
\hline & 120 & $\times$ & $\triangle$ & $\triangle$ & $\bigcirc$ & $\triangle$ & $\bigcirc$ & $\bigcirc$ & $\triangle$ & $\bigcirc$ & (a) & $\triangle$ & $\bigcirc$ & $\bigcirc$ & $\triangle$ & $\bigcirc$ & $\bigcirc$ & $\triangle$ & $\bigcirc$ & (a) \\
\hline & 150 & $\triangle$ & $\triangle$ & 0 & 0 & $\triangle$ & 0 & (a) & 0 & 0 & (a) & $\triangle$ & $\triangle$ & 0 & $\triangle$ & 0 & (a) & $\triangle$ & 0 & (a) \\
\hline \multirow{5}{*}{ PM20 } & $26^{\circ} \mathrm{C}$ & $x$ & $x$ & $x$ & $\triangle$ & $x$ & $\triangle$ & $\triangle$ & $\triangle$ & $\triangle$ & 0 & & & & & & & & & \\
\hline & 80 & & $\triangle$ & $\triangle$ & $\bigcirc$ & 0 & 0 & (a) & $\bigcirc$ & (a) & (a) & & & & & & & & & \\
\hline & 100 & $\triangle$ & $\triangle$ & $\bigcirc$ & $\bigcirc$ & $\triangle$ & $\bigcirc$ & (a) & $\bigcirc$ & $\bigcirc$ & (a) & & & & & & & & & \\
\hline & 120 & $\triangle$ & $\bigcirc$ & 0 & $\bigcirc$ & $\bigcirc$ & 0 & (0) & $\bigcirc$ & (0) & (a) & & & & & & & & & \\
\hline & 160 & & $\triangle$ & $\triangle$ & 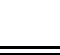 & $\triangle$ & ? & ? & $\triangle$ & & 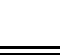 & & & & & & & & & \\
\hline \multirow{5}{*}{ TerM } & $23^{\circ} \mathrm{C}$ & $x$ & $x$ & $\triangle$ & $\triangle$ & $\triangle$ & $\triangle$ & $\triangle$ & $\triangle$ & $\triangle$ & $\triangle$ & $x$ & $\triangle$ & $\triangle$ & $\triangle$ & $\triangle$ & 0 & $\triangle$ & 0 & 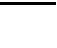 \\
\hline & 80 & & $\triangle$ & $\triangle$ & $\bigcirc$ & $\triangle$ & $\triangle$ & $\bigcirc$ & $\triangle$ & $\bigcirc$ & (0) & $\triangle$ & $\triangle$ & 0 & $\triangle$ & 0 & $\bigcirc$ & $\triangle$ & 0 & (a) \\
\hline & 100 & & $\triangle$ & 0 & $\bigcirc$ & $\triangle$ & 0 & (0) & $\bigcirc$ & (a) & (a) & $\triangle$ & $\bigcirc$ & $\bigcirc$ & $\triangle$ & 0 & (a) & $\triangle$ & (a) & () \\
\hline & 120 & & $\triangle$ & 0 & $\bigcirc$ & $\triangle$ & $\bigcirc$ & & $\triangle$ & $\bigcirc$ & 0 & $\triangle$ & $\bigcirc$ & $\bigcirc$ & $\triangle$ & 0 & (a) & $\triangle$ & 0 & () \\
\hline & 150 & & $\triangle$ & 0 & 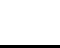 & 0 & 0 & & 0 & 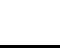 & 0 & $\triangle$ & 0 & 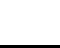 & 0 & 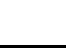 & 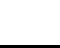 & $\triangle$ & 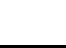 & \\
\hline
\end{tabular}

${ }^{\mathrm{a}} \times$ : no change, $\triangle$ : layer was slightsy damaged by brushing, $\bigcirc$ : layer was partly removed, ๑: layer was completely removed, $\bullet$ : most of the layer was removed, leaving a thin residual layer.
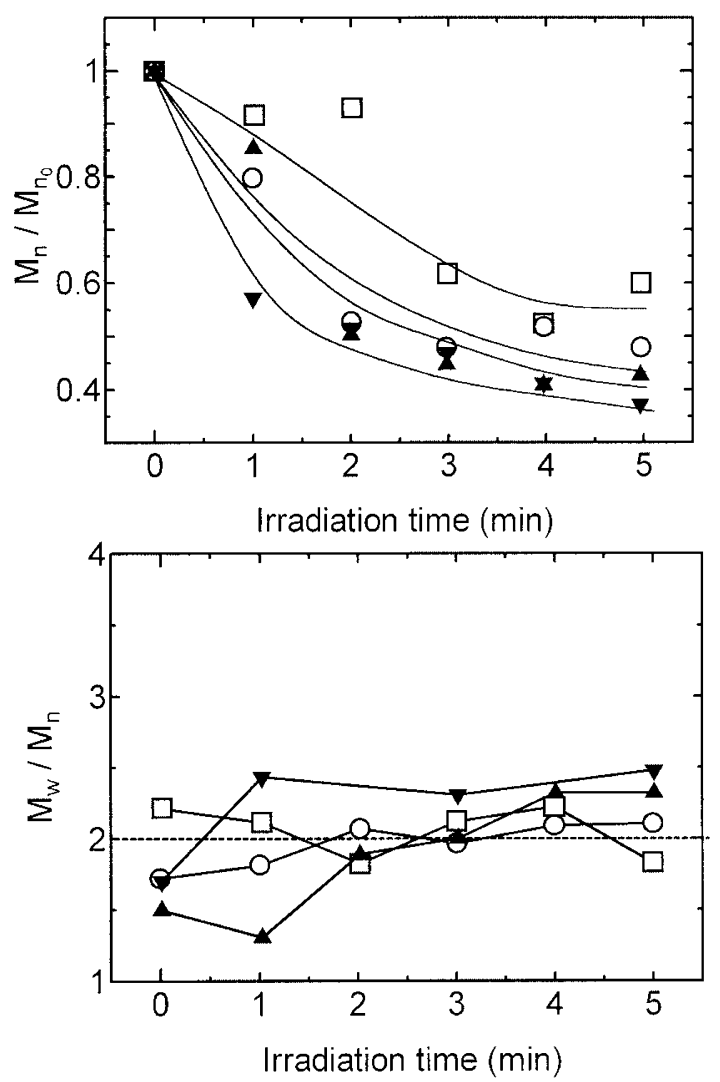

Figure 1. PIPK-content dependence of MW (above) and MWD (below) changes after $254 \mathrm{~nm}$ DUV irradiation at $150{ }^{\circ} \mathrm{C}$. ( $M_{\mathrm{n}_{\mathrm{o}}}$ : initial MW; 口: PM05; ○: PM11; $\mathbf{\Delta}$ : PM15; v: PM20). monotonous decrease of MW as shown in Figure 2 (b). The decreasing rates with PM11 irradiated at $26^{\circ} \mathrm{C}$ and at $80^{\circ} \mathrm{C}$ were larger, while the rates at $120^{\circ} \mathrm{C}$ and $150^{\circ} \mathrm{C}$ were smaller than those in the case of $254 \mathrm{~nm}$ DUV irradiation at the same temperature. The MWD remained almost constant around the initial value of 1.7 for the first $5 \mathrm{~min}$, suggesting the main photoreaction at $26-150^{\circ} \mathrm{C}$ was degradation, and crosslinking was negligible. After calibrating the lower absorbance by the photoactive moiety and the higher absorbance by the inactive part of the copolymer at $222 \mathrm{~nm}$, the quantum yield for main chain scission, $\phi \mathrm{cs}$, was calculated and is plotted against the irradiation temperature in Figure 3 (b). Comparison with Figure 3 (a) indicates that $\phi \mathrm{cs}$ by $222 \mathrm{~nm}$ light was quite similar to or a little higher than $\phi \mathrm{cs}$ by $254 \mathrm{~nm}$ light.

UV Spectral Change by DUV Irradiation and Quantum Yield, $\phi s r$. While PIPK-MMA copolymer was irradiated by $254 \mathrm{~nm}$ DUV light, the absorption band at $242 \mathrm{~nm}$ due to benzoyl group decreased gradually. Two examples of UV spectral changes with PM1 1 at $26^{\circ} \mathrm{C}$ and $150{ }^{\circ} \mathrm{C}$ are shown in Figure 4 (a). The quantum yield calculated for benzoyl side-group removal, $\phi \mathrm{sr}$, is shown also in Figure 3 (a). The figures demonstrate that the yield of side-group removal increased as the temperature increased, which is reasonable for the bulky 

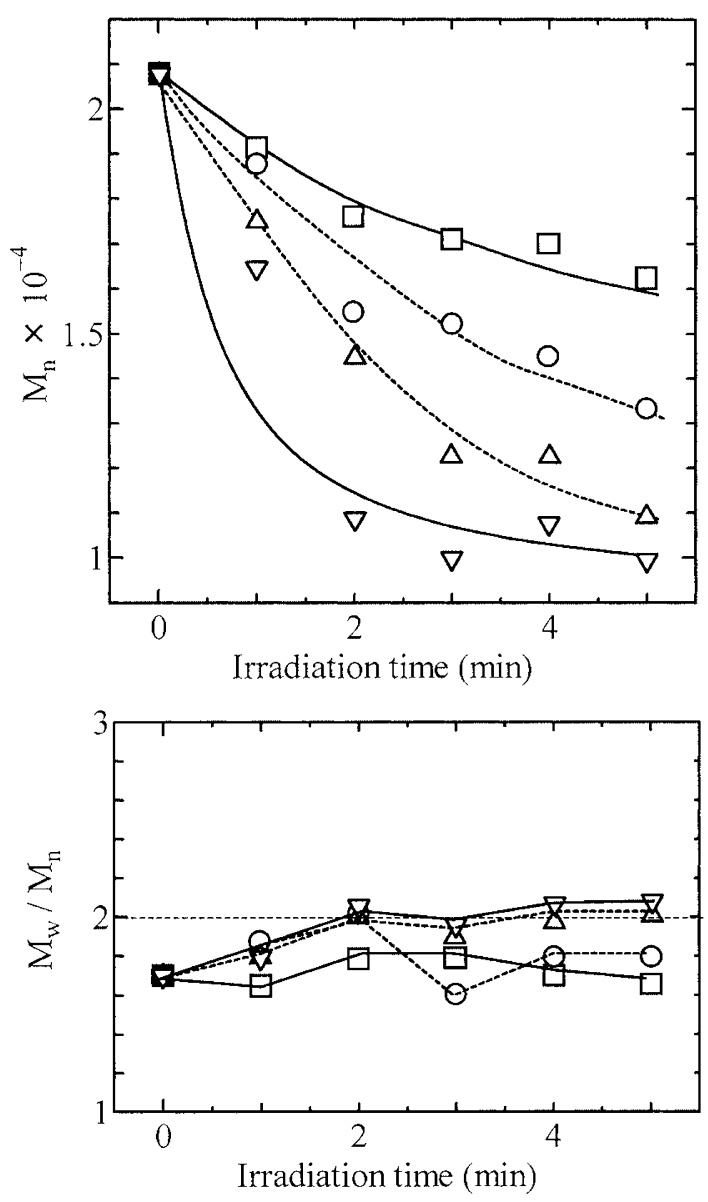

(a)
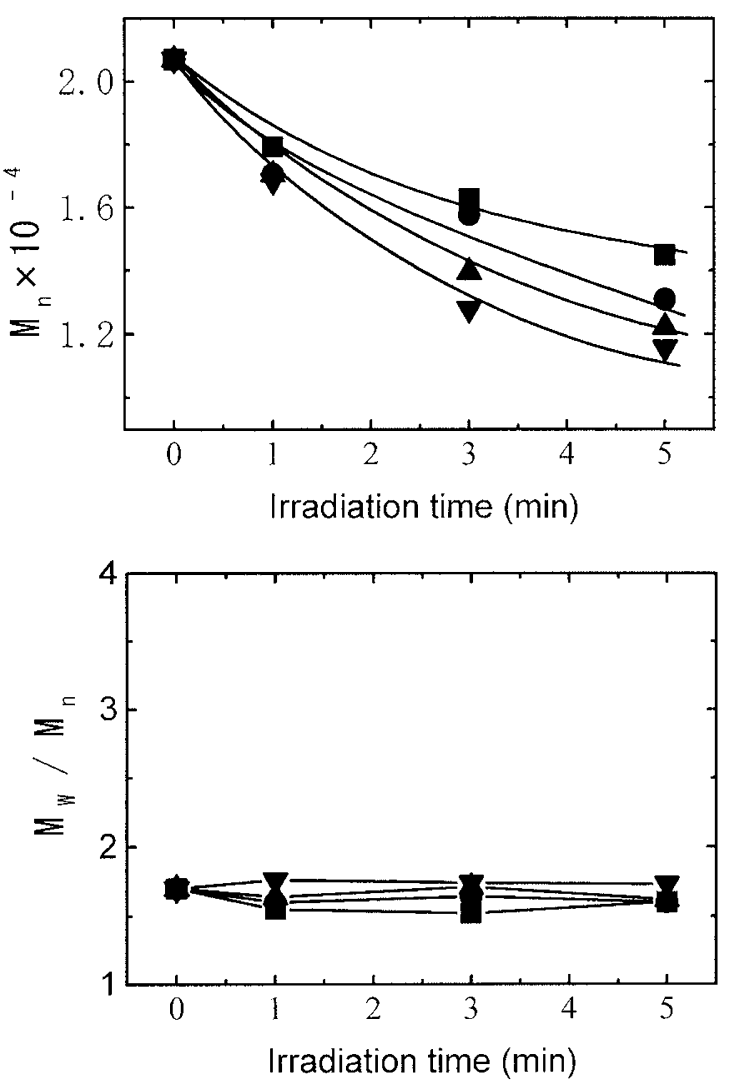

(b)

Figure 2. Temperature dependence of MW (above) and MWD (below) changes of PM1 1 (a) after $254 \mathrm{~nm}$ DUV irradiation ( $\square: 26^{\circ} \mathrm{C}$; $\circ$ : $\left.80^{\circ} \mathrm{C} ; \triangle: 120^{\circ} \mathrm{C} ; \nabla: 150^{\circ}\right)$, (b) after $222 \mathrm{~nm}$ DUV irradiation $\left(\mathbf{-}: 26^{\circ} \mathrm{C} ; \bullet: 80^{\circ} \mathrm{C} ; \mathbf{\Lambda}: 120^{\circ} \mathrm{C} ; \mathbf{v}: 150^{\circ}\right)$.

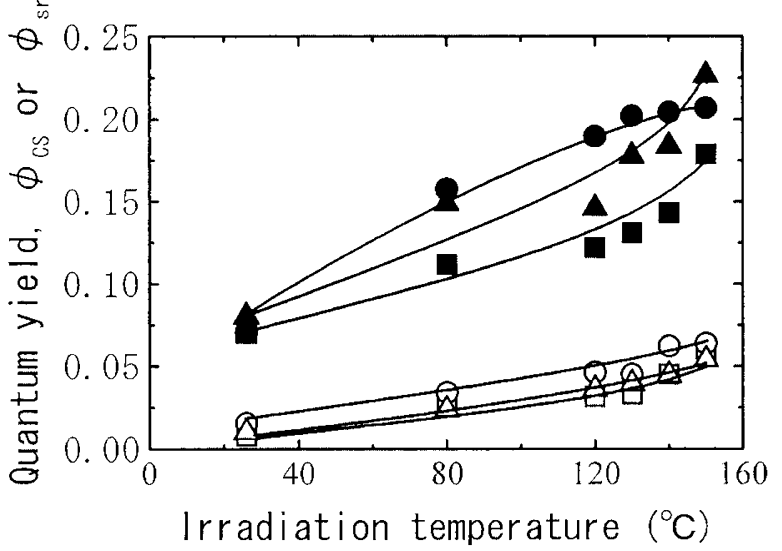

(a)

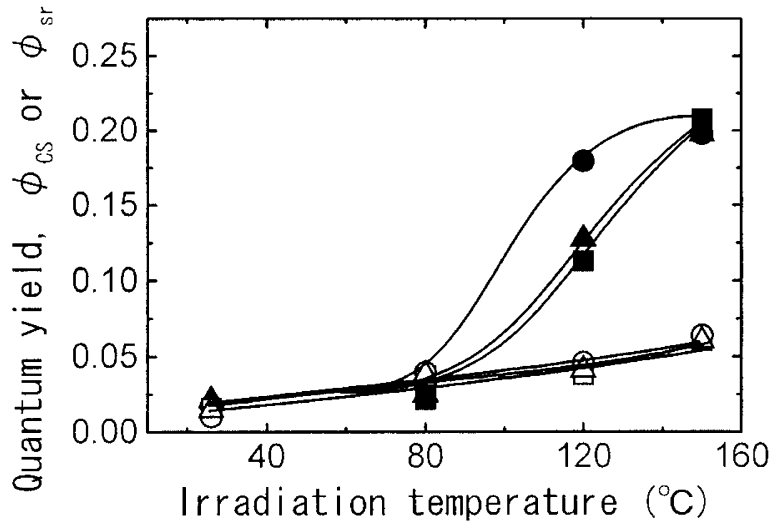

(b)

Figure 3. PIPK-content dependence of quantum yields for main-chain scission, $\phi \mathrm{cs}$, (hollow symbols) and for side-group removal, $\phi \mathrm{sr}$,

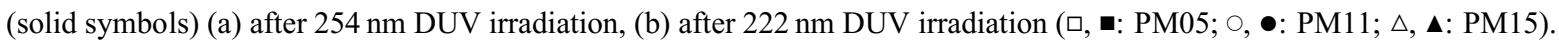

benzoyl group to require large free volume for escaping from the reaction cage after Norrish Type I splitting.

Another couple of examples of UV spectral changes by $222 \mathrm{~nm}$ DUV irradiation at $26^{\circ} \mathrm{C}$ and $150^{\circ} \mathrm{C}$ are demonstrated in Figure 4 (b). One of the most outstanding characteristics is the spectral change at room temperature (Figure 4 (b), left) quite different from that ob- served by $254 \mathrm{~nm}$ DUV irradiation (Figure 4 (a), left), though the difference was not so striking in the case of DUV irradiation at $150^{\circ} \mathrm{C}$ (Compare Figure 4 (b), right with Figure 4 (a), right). Little decrease in intensity of the absorption band at $242 \mathrm{~nm}$ demonstrates that benzoyl side-group removal by Norrish Type I splitting was not the main photoreaction by $222 \mathrm{~nm}$ DUV irradiation 

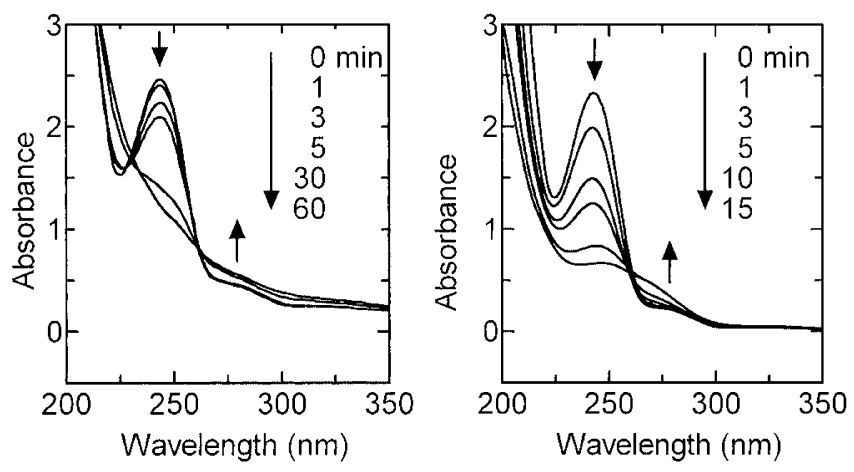

(a)
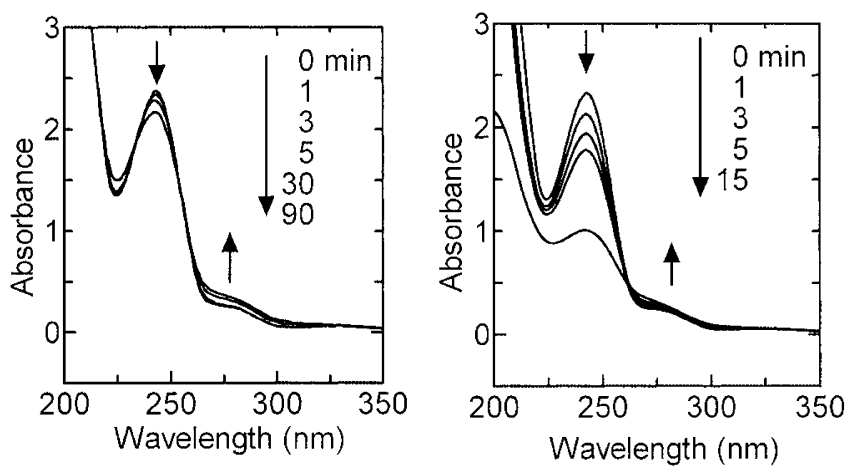

(b)

Figure 4. UV Spectral change of PM11 (a) after $254 \mathrm{~nm}$ DUV irradiation, (b) after $222 \mathrm{~nm}$ DUV irradiation at $26^{\circ} \mathrm{C}$ (left) and $150^{\circ} \mathrm{C}$ (right). at room temperature.

Temperature dependence of $\phi \mathrm{sr}$ by $222 \mathrm{~nm}$ light is shown in Figure 3 (b). The $\phi$ sr's at $26{ }^{\circ} \mathrm{C}$ and at $80^{\circ} \mathrm{C}$ were much smaller than those by $254 \mathrm{~nm}$ light, which presents a remarkable contrast to the results that $\phi$ sr's at $120^{\circ} \mathrm{C}$ and at $150^{\circ} \mathrm{C}$ were fairly indifferent to the wavelength of irradiating DUV light.

Photodegradation Mechanism of PIPK-MMA Copolymer. Based on the temperature dependence of $\phi$ sr and $\phi \mathrm{cs}$ and their mutual relation reported in the former paper, ${ }^{4}$ we have already proposed Reactions (a)-(e), and (b')-(d') in Figure 5.

In addition, depolymerization ( $\mathrm{g}$ ) may follow $\beta$ scission (b), as the intensity of UV spectrum decreased in the wide wavelength range after DUV irradiation at higher temperature (cf. UV-spectral changes at $150^{\circ} \mathrm{C}$ shown in Figure 4 (a) and Figure 4 (b), right).

Polymer Radical A, which is generated by benzoyl side-group removal (a), cannot form crosslinking through recombination with the polymer radical to be generated by abstraction of $\alpha$-hydrogen from the polyvinyl group, since PIPK-MMA copolymer contains no vinyl monomer unit. Then, a reaction to be considered for crosslinking (Reaction (f)) is that through mutual recombination of Polymer Radicals A.<smiles>CCC(C)(CCC(C)(C)C(=O)O)C(=O)c1ccccc1</smiles><smiles>COC(=O)C(C)(C)CCC(C)(CC=O)C(=O)c1ccccc1</smiles><smiles>C=C</smiles><smiles>[CH2+]CC(C)(CC)C(=O)c1ccccc1</smiles><smiles>CC(C)(C)OC(=O)C(C)(C)C(=O)C(C)(C)C</smiles>
$h \nu \cdot \uparrow(h)$<smiles>CCC(C)(CC(C)(C)C(=O)O)C(=O)c1ccccc1</smiles><smiles>C=C=C</smiles>

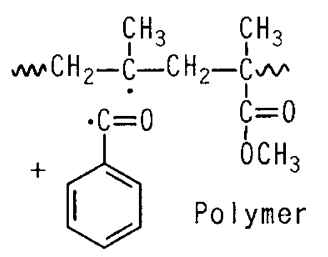

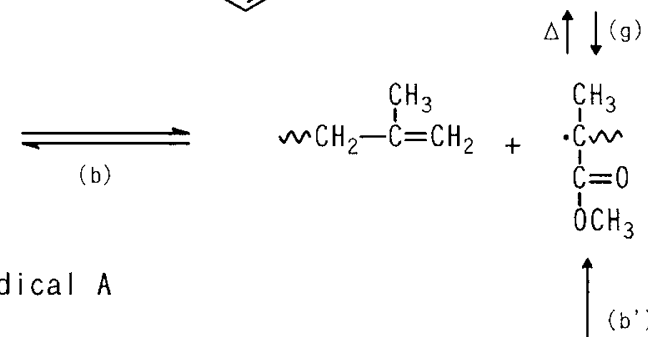<smiles>CC(C)C(C)(C)C(C)C(C)(C)C(C)C(=O)O</smiles>

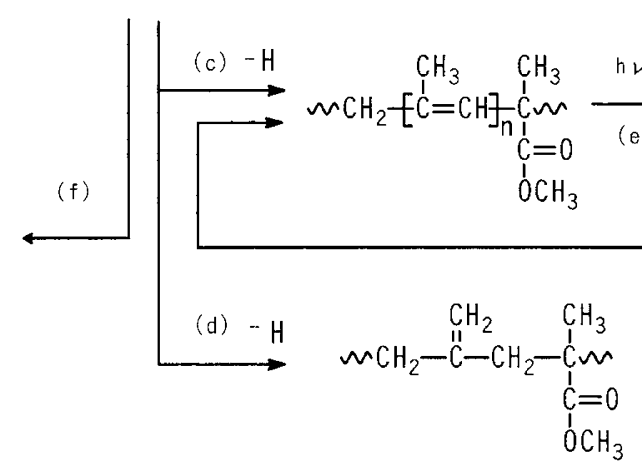

Figure 5. Degradation scheme of PIPK-MMA copolymer: (a) benzoyl side-group removal by Norrish Type I to form Polymer Radical $\mathrm{A}$, (b, b') $\beta$-scission of the main chain, (c, d) hydrogen abstraction to form $\mathrm{C}=\mathrm{C}$ bond, (e) photolysis of ester side group on the carbon atom adjacent to the $\mathrm{C}=\mathrm{C}$ bond, (c', d') hydrogen abstraction leading to extension of conjugate double bond, (f) crosslinking by mutual recombination of Polymer Radicals A, (g) depolymerization to generate vinylidene monomer, and (h) direct photolysis of $\mathrm{C}-\mathrm{C}$ bond in the main chain. 
Both experimental results that the highest $\phi \mathrm{cs}$ was observed with PM11 and that the optimum temperature for detaching was found to be 20-50 degree above $T_{\mathrm{g}}$ may justify the mechanism: main-chain scission by Reaction (b) is the 1st order, while crosslinking (f) by mutual recombination is the 2nd order reaction of Polymer Radical A. Then, the residual layer formation at higher concentration or at higher temperature was reasonably ascribed to the highly accelerated crosslinking caused by the 2 nd order reaction. Based on these observation and consideration, we concluded that the mutual recombination is regarded as one of the main reactions for crosslinking (f) in Figure 5.

When the copolymer layer was irradiated by $222 \mathrm{~nm}$ DUV light at $120^{\circ} \mathrm{C}$ or $150^{\circ} \mathrm{C}$, which was around or above $T_{\mathrm{g}}$, the correlation between $\phi \mathrm{cs}$ and $\phi \mathrm{sr}$ was similar to that observed by $254 \mathrm{~nm}$ DUV light (compare Figure 3 (b) with Figure 3(a)). Therefore, the same chemistry seems to hold good in photodegradation at these temperature ranges. On the contrary, $222 \mathrm{~nm}$ DUV irradiation at room temperature or at $80^{\circ} \mathrm{C}$ brought about main-chain scission with reduced occurrence of benzoyl side-group removal, which suggested the scission by a mechanism other than Reaction (b). Considering the paper ${ }^{5}$ on the photolysis of methacrylate polymers caused by $185 \mathrm{~nm}$ DUV irradiation, the degradation by $222 \mathrm{~nm}$ DUV light also proceeded through direct scission of the $\mathrm{C}-\mathrm{C}$ bond in the main chain, Reaction (h). Further, some of the carbon radicals formed by the main-chain scission may be followed by depolymerization (g).

The improved detachability observed with the layers after $222 \mathrm{~nm}$ DUV irradiation below $T_{\mathrm{g}}$ is likely to be ascribed to this direct scission of the main chain without generating Polymer Radical A.

\section{Photodegradation of PIPK-St-BuA Matrix Terpolymer by DUV Irradiation}

Detachability of the Polymer Layer from the Substrate. When the layer of terpolymer containing $11 \mathrm{~mol} \%$ of PIPK, TerM, was irradiated by $254 \mathrm{~nm}$ DUV light, as is shown in the under-left part of Table II, it was removed after 3 cycles of 5 min DUV irradiation at $80^{\circ} \mathrm{C}$ or 3 cycles of 3 min DUV irradiation at $100^{\circ} \mathrm{C}$ followed by brushing. The high detachability at $80^{\circ} \mathrm{C}$ and $100^{\circ} \mathrm{C}$ was quite similar to that with PM11 after DUV irradiation at $120^{\circ} \mathrm{C}$ and $150^{\circ} \mathrm{C}$, where the temperatures were 5-50 degree above $T_{\mathrm{g}}$ and below the softening point, $T_{\mathrm{s}}$, of each polymer. After DUV irradiation at $120^{\circ} \mathrm{C}$ and $150^{\circ} \mathrm{C}$, the residual layer was observed to remain, and the detachability of TerM was much lower than that of PM20 at $100^{\circ} \mathrm{C}$ and $120^{\circ} \mathrm{C}$, where the temperatures were above $T_{\mathrm{s}}$ of both poly-
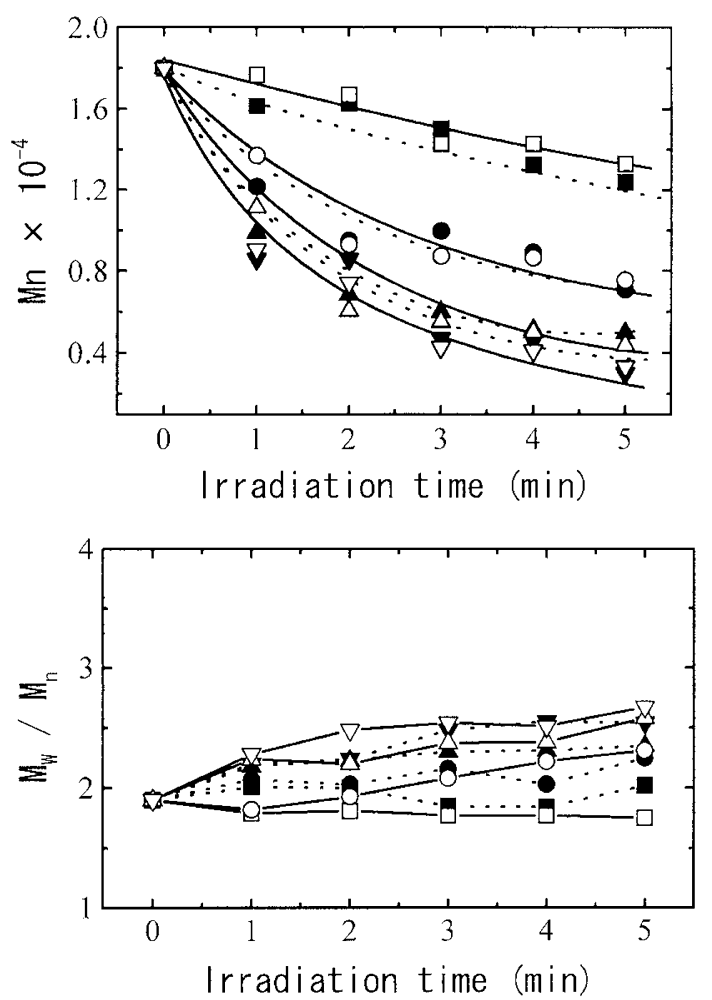

Figure 6. Temperature dependence of MW (above) and MWD (below) changes of TerM after DUV irradiation (hollow symbols: $254 \mathrm{~nm}$; solid symbols: $222 \mathrm{~nm}$; 口, $\mathbf{\square}: 26^{\circ} \mathrm{C}$; $, \bullet: 80^{\circ} \mathrm{C} ; \Delta, \mathbf{\Delta}$ : $\left.120^{\circ} \mathrm{C} ; \nabla, \mathbf{v}: 150^{\circ} \mathrm{C}\right)$.

mers. The lower detachability seems to indicate promotion of crosslinking in the case of PIPK-St-BuA terpolymer.

The results after DUV irradiation by the excimer lamp emitting $222 \mathrm{~nm}$ light are shown in the under-right part of Table II. When the TerM layer was irradiated at room temperature, the detachability by the excimer lamp was low or moderate and similar to that of TerM by the Hg lamp emitting $254 \mathrm{~nm}$ light, but obviously lower than that of PM11 by the excimer lamp. When the TerM layer was irradiated at $80^{\circ} \mathrm{C}$ and $100^{\circ} \mathrm{C}$, the detachability was high and no appreciable difference was made between the DUV light sources. The detachability in this temperature range corresponded to that of PM1 1 at $120^{\circ} \mathrm{C}$ and $150{ }^{\circ} \mathrm{C}$, above $T_{\mathrm{g}}$ and below $T_{\mathrm{s}}$. The detachability after DUV irradiation by the excimer lamp at $120^{\circ} \mathrm{C}$ was much higher than that by the $\mathrm{Hg}$ lamp, which was an unexpected result and will be discussed later.

$M W$ and MWD Changes by DUV Irradiation. MW's of TerM decreased monotonously by DUV irradiation as shown in Figure 6, and the decreasing rate was faster as the temperature became higher. The decreasing rate during $222 \mathrm{~nm}$ DUV irradiation at $23^{\circ} \mathrm{C}$ was larger, while the rate at $150^{\circ} \mathrm{C}$ was smaller than that during $254 \mathrm{~nm}$ DUV irradiation at the same temperature. MWD changes after DUV irradiation at var- 

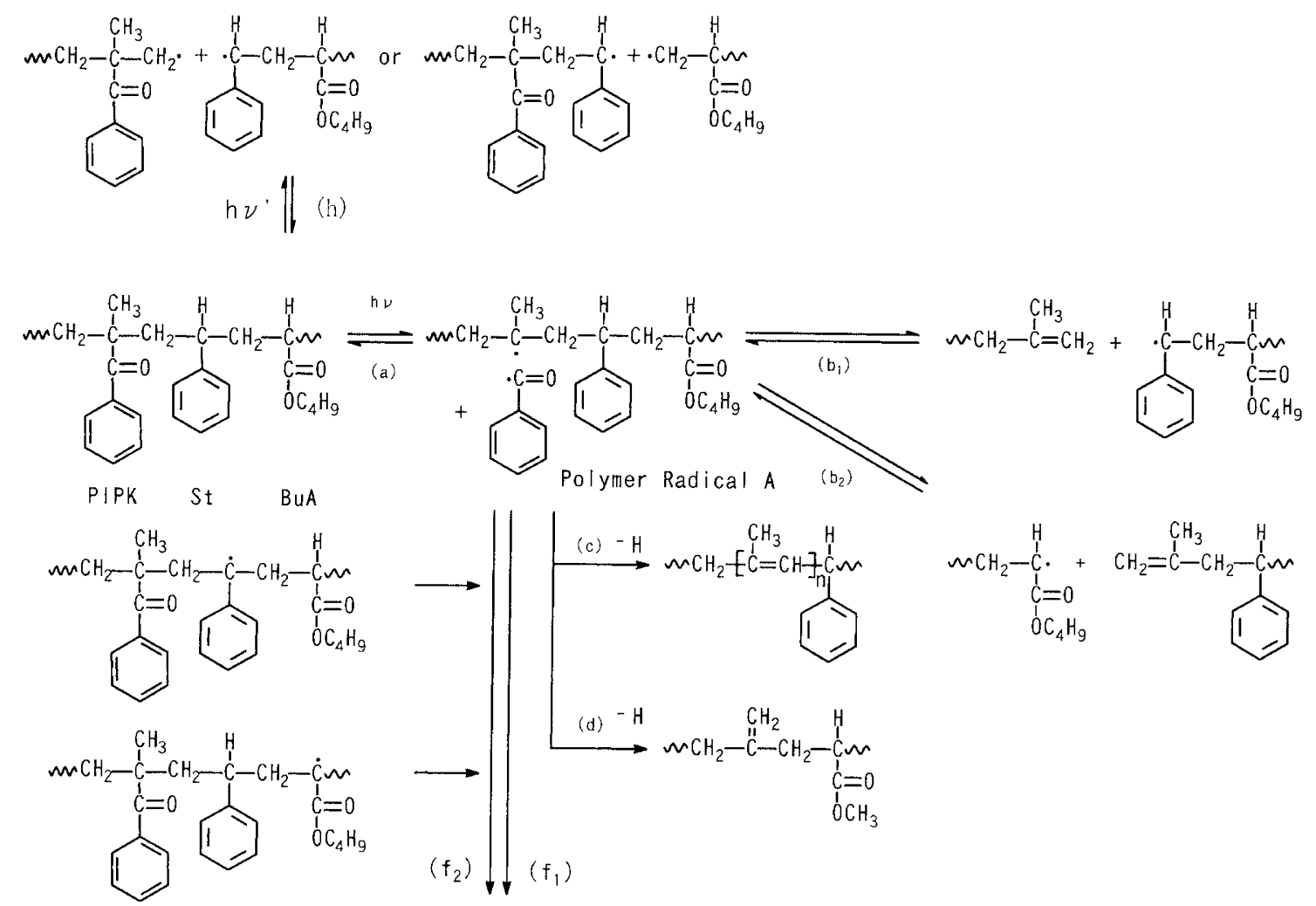

Figure 7. Degradation scheme of PIPK tercopolymer: (a) benzoyl side-group removal by Norrish Type I to form Polymer Radical A, $\left(b_{1}, b_{2}\right) \beta$-scission of the main chain, (c, d) hydrogen abstraction to form $\mathrm{C}=\mathrm{C}$ bond, $\left(\mathrm{f}_{1}\right)$ crosslinking by mutual recombination of Polymer Radicals A, $\left(\mathrm{f}_{2}\right)$ crosslinking by recombination of Polymer Radical A with the polymer radical formed by H-abstraction from the vinyl monomer unit, and (h) direct photolysis of $\mathrm{C}-\mathrm{C}$ bond in the main chain.

ious temperatures are shown also in Figure 6. When the TerM layer was irradiated by $254 \mathrm{~nm}$ DUV light at $120^{\circ} \mathrm{C}$ or $150^{\circ} \mathrm{C}$ and by $222 \mathrm{~nm}$ at $150^{\circ} \mathrm{C}$, MWD increased over 2.5 , which corresponded to the residual layer formation. However, $222 \mathrm{~nm}$ DUV irradiation at $120^{\circ} \mathrm{C}$ for $3-5$ min brought about MWD increase to about 2.3, but the layer was removed completely.

UV-Spectral Change by DUV Irradiation. The TerM layer was similarly irradiated by $254 \mathrm{~nm}$ or $222 \mathrm{~nm}$ DUV light at $23^{\circ} \mathrm{C}$ and $150^{\circ} \mathrm{C}$. The absorption band at $242 \mathrm{~nm}$ overlapped with the aromatic and olefinic $\mathrm{C}=\mathrm{C}$ bands due to the styrene monomer unit and/or the photoproducts, ${ }^{6}$ and the benzoyl side-group removal was not able to be followed by the spectral change. The number of quanta absorbed by the benzoyl moiety at $254 \mathrm{~nm}$ or $222 \mathrm{~nm}$ could not be estimated quantitatively, either, and neither $\phi \mathrm{cs}$ nor $\phi$ sr was calculated for TerM.

The spectral changes during $254 \mathrm{~nm}$ and $222 \mathrm{~nm}$ DUV irradiation at $150^{\circ} \mathrm{C}$ included decreases of the absorption bands at $190-220 \mathrm{~nm}$ and $230-250 \mathrm{~nm}$ and an increase of the band at $250-350 \mathrm{~nm}$. The decreases indicated thinning of the polymer layer as well as benzoyl side-group removal, and the increase $\operatorname{did} \mathrm{C}=\mathrm{C}$ bond formation.
Photodegradation Mechanism of PIPK Terpolymer. The lower detachability of TerM than PM11 observed after $222 \mathrm{~nm}$ DUV irradiation at room temperature, $254 \mathrm{~nm}$ DUV irradiation at $120^{\circ} \mathrm{C}$, and $254 \mathrm{~nm}$ and $222 \mathrm{~nm}$ DUV irradiation at $150^{\circ} \mathrm{C}$ pointed out the promotion of crosslinking, which must be resulted from incorporation of vinyl monomer units such as St and $\mathrm{BuA}$ in the polymer chain. Though the benzoyl sidegroup removal from PIPK-St-BuA terpolymer could not be estimated quantitatively by UV spectral change, degradation mechanism similar to that of PIPK-MMA copolymer is considered as indicated in Figure 7: (a) benzoyl side-group removal by Norrish Type I to form Polymer Radical A, $\left(\mathrm{b}_{1}, \mathrm{~b}_{2}\right) \beta$-scission of the main chain, (c, d) hydrogen abstraction to form $\mathrm{C}=\mathrm{C}$ bond, $\left(\mathrm{f}_{1}\right)$ crosslinking by mutual recombination of Polymer Radicals $A,\left(f_{2}\right)$ crosslinking by recombination of Polymer Radical A with the polymer radical formed by $\mathrm{H}-$ abstraction from the vinyl monomer unit, and (h) direct photolysis of $\mathrm{C}-\mathrm{C}$ bond in the main chain.

Photoinduced reactions, (a) and (h), may proceed slower because of the filtering effect by the aromatic and/or olefinic $\mathrm{C}=\mathrm{C}$ bands. ${ }^{6}$ Depolymerization (g) takes place scarcely on account of low content of vinylidene monomer, PIPK. Photolysis of ester side group (e) is hard to occur with n-butyl acrylate unit. 
The styrene and n-butyl acrylate units will generate the other types of polymer radicals after abstraction of $\alpha$-hydrogen on the polyvinyl group, and contribute to formation of additional crosslinking by recombination with Polymer Radical A $\left(\mathrm{f}_{2}\right)$.

In spite of the retarded photodegradation and the promoted crosslinking in the terpolymer compared with the model copolymer, overall degradation was still the main photoreaction by DUV irradiation, since the terpolymer layer was observed to be detached actually after 2-3 times of repeated cycles of 3-5 min DUV irradiation at $80-100^{\circ} \mathrm{C}$ followed by brushing.

The detachability observed after DUV irradiation by the excimer lamp at $120^{\circ} \mathrm{C}$ was an unexpected result, while the residual layer remained by the $\mathrm{Hg}$ lamp at the same temperature. The difference may be due to the wavelength of the irradiating light or the atmosphere, in nitrogen or in air, in which the DUV sources were operated, so additional DUV irradiation experiments by the Hg lamp in nitrogen are needed for further elucidation of the mechanism.

\section{CONCLUSION}

A coating layer of $11 \mathrm{~mol} \%$ PIPK-containing terpolymer with $\mathrm{St}$ and $\mathrm{BuA}$ was detached completely from the substrate by $2-3$ cycles of $254 \mathrm{~nm}$ or $222 \mathrm{~nm}$ DUV irradiation for $3-5 \mathrm{~min}$ at $80-100{ }^{\circ} \mathrm{C}$ followed by brushing.

The reaction scheme was clarified by GPC analysis and UV-spectral change on the PIPK-MMA model copolymer as well as the terpolymer. Photodegradation of the terpolymer proceeded by $\beta$-scission of Polymer Radical A on the main chain, which was generated by the benzoyl side-group removal from the PIPK unit, and by direct photolysis of the $\mathrm{C}-\mathrm{C}$ bond in the main chain. In parallel with photodegradation, photo- crosslinking took place through 2 types of recombination: that of Polymer Radicals A with each other and that of Polymer Radical A with the other polymer radicals generated by $\mathrm{H}$-abstraction from the polyvinyl groups in St and BuA units.

DUV irradiation under the conditions abovementioned brought about an overall degradation to remove the polymer layer successfully, but DUV irradiation with the copolymer and terpolymer with higher PIPK content or at higher temperature caused photocrosslinking besides photodegradation to form the thin residual layer on the substrate.

$222 \mathrm{~nm}$ DUV radiation was more effective than $254 \mathrm{~nm}$ one, as the irradiation at $120^{\circ} \mathrm{C}$ made the terpolymer layer possible to be detached from the substrate, and, however, difference in the degradation scheme is not clear at present.

Acknowledgment. The authors would like to thank Messrs. Tatsumi Hiramoto and Nobuyasu Ishigaki of Ushio Inc. for providing facility for use of the $\mathrm{KrCl} \mathrm{ex-}$ cimer lamp.

\section{REFERENCES}

1. K. Sugita, M. Shimizu, T. Okuno, M. Kushida, K. Harada, K. Saito, N. Namatame, and N. Mogi, Polym. J., 28, 637 (1996).

2. K. Sugita, T. Ishizawa, H. Tateno, M. Kushida, K. Harada, K. Saito, N. Namatame, and N. Mogi, Polym. J., 32, 330 (2000).

3. K. Sugita, N. Ueno, K. Harada, M. Kushida, Y. Suzuki, Y. Takeuchi, and J. E. Guillet, Polym. J., 25, 1059 (1993).

4. K. Sugita, T. Ishida, M. Kushida, K. Harada, K. Saito, and N. Ueno, Can. J. Chem., 73, 1841 (1995).

5. M. Shirai, T. Yamamoto, and M. Tsunooka, Polym. Degrad. Stab., 63, 481 (1999).

6. J. O. Choi, J. A. Moore, J. C. Corelli, J. P. Silverman, and H. Bakhru, J. Vac. Sci. Technol., B, 6, 2286 (1988). 